\title{
Developing a Collective Awareness Platform for Urban Sustainability Challenges: Case Study of the POWER Project
}

\author{
Mathias Becker ${ }^{1}$, Ksenia Koroleva ${ }^{1}$, Kalina Drenska ${ }^{1}$, Diogo Vitorino ${ }^{2}$ and \\ Jasminko Novak ${ }^{1,3}$
}

\begin{abstract}
In this paper we describe the socio-technical approach developed in the POWER project extending traditional forms of citizen engagement for local sustainability challenges with a collective awareness platform in order to increase public awareness, knowledge and engagement. We show how a citizencentered design and implementation process integrating different technological enablers such as gamification, real-time open data integration or knowledge visualization results in a platform for sustainability issues that can drive collective awareness and collaborative knowledge sharing. Against the background of four different pilot cities with distinct water-related sustainability challenges, we present the implementation of the local platforms and how these have been effectively used by almost 1.000 active users, supporting an innovative engagement model that employed collaborative open innovation in online and offline settings for citizen-driven solution development to local sustainability challenges. We present the results from three series of citizen workshops where 150 participants provided valuable feedback, which was integrated in the further platform improvement. The evaluation confirmed its usability, enabling platform uptake among the target groups and its social impact by increasing awareness and knowledge. Finally, we derive a set of implications for similar initiatives addressing sustainability challenges helping them to overcome common barriers to participation and engagement.
\end{abstract}

Keywords: citizen engagement, digital citizenship, sustainable urbanism, education, governance sustainability, gamification, water conservation, disaster risk reduction

\section{Introduction}

Recent developments in policy making around Europe revive traditional forms of governance by promoting participatory democracy and changing the relations between the state and the public. Resulting from these changes in the context of socio-technical developments, new governance approaches are needed to harness the dynamic societal forces to sustainable decisions (Manara, Pianosi, Tavanti, Ferrari, Ozawa-Meida, Becker et al. 2019). Governance - as the structure and the processes for collective decisionmaking involving governmental and non-governmental actors - also includes a 'cognitive dimension' or modes of thought as a relevant component of dynamic governance activity (Irwin, 2001; Renn, 2008). Against this background, the POWER project is building collective awareness platforms for water-related sustainability issues. It aims to engage citizens, professionals and politicians to participate in sharing knowledge and addressing local water sustainability issues, by a combination of changing policies, applying best professional practices and modifying personal attitudes, knowledge and behaviours. By

| ${ }^{1}$ European Institute for Participatory Media e. V., Pariser Platz 6, 10117 Berlin, Germany

${ }^{2}$ Baseform Aggregate Formula, Lda, Rua Borges Carneiro 34 Rc, Lisboa, 1200-619, Portugal

${ }^{3}$ University of Applied Sciences Stralsund, IACS - Institute for Applied Computer Science, Schwedenschanze 15, 18435 Stralsund 
mobilising social actions, POWER aims to support responses to environmental sustainability challenges with local strategies through incentive schemes for online collaboration and through education campaigns enhancing knowledge and building capacity and making available to all citizens.

In the POWER project a collective awareness platform has been developed facilitating the digital involvement of local communities in the processes of governance, planning and decision-making, and targets three tiers of audience: citizens, water professionals and politicians. The Platform focuses on four key water-related issues: water scarcity, water conservation, water quality and flood risk. These topics are initially explored in the context of four different pilot cities: Jerusalem, Milton Keynes, Sabadell and Leicester. The local collective awareness platforms present an innovative way to engage citizens in the challenge at hand. Such environmental challenges are complex, and affect multiple actors on a range of scales. Their management demands transparent and flexible decision-making processes that integrates different knowledge and values, i.e. not only the one of experts and policy makes, but also those of the general public (Webler, Kastenholz \& Renn 1995; Krueger, Tuler \& Webler 2001; Petts \& Brooks 2006). Achieving the engagement of the wider public has been key to the success of the POWER project and in this paper we present some of our approaches to achieve this.

\section{The POWER Approach}

The overarching aim of the EU-funded Horizon 2020 project POWER (Political and sOcial awareness on Water EnviRonmental challenges) is to share the knowledge and experience of water scarcity, security, quality and water consumptionrelated issues in different EU local authorities, using a user-driven approach. This aim is achieved through the attainment of the following objectives (Manara, Pianosi, Tavanti, Ferrari, Ozawa-Meida, Becker et al. 2019):

- Setting up a direct participatory process to gather evidence from stakeholders and environment data for an enhanced awareness able to influence individual and collective sustainable behaviour and to exert real influence on policy-making.

- Sharing progress, knowledge, opinions and best practices in an open consultation as well as the implementation of a collective awareness platform to support sustainable behaviour and extending a raised collective awareness on the environment and the consequences of our actions.

- Mobilising social actions to respond to climate change with local strategies through incentive schemes for online collaboration and through education campaigns enhancing knowledge and building capacity and making available to all citizens.

The POWER collective awareness platforms connect top-down, middle-out and bottomup interactions to enable flows of information between the different types of stakeholders, above all citizens, city administrations and professional experts. They provide information on water issues and advice on best-practices of relevance to the local communities that is otherwise unavailable or difficult to find, in an easily accessible, timely manner. They also offer channels of interaction and knowledge sharing between local communities and with the municipality. To support awareness and stimulate 
engagement, the information provision, user interaction and knowledge sharing channels and functionalities integrate visualisation and gamification techniques. The information on local needs, the experiences and knowledge created and communicated also enable the identification and sharing of community-driven best practices, stemming from local experience. In a best practice repository, both the knowledge and lessons learned from top-down analysis and expert exchanges about them, and the community-driven exchange and identification of best local practices are connected with each other.

To achieve this, the POWER collective awareness platform is designed in an open and modular way addressing the specific needs of the different actors and target groups, and of the different channels of information provision, interaction and knowledge sharing. Far from being a very complex website, the POWER platform is meant for the general public, which means that the target audience is difficult to predict. Thus, it is critical to perform functional testing on the different web browsers and operating systems, in order to minimize any differences between them and any erroneous behaviour (Elelman, Becker, Drenska, Fernandes, Coelho, Koop, et al. 2019).

\section{Socio-Technical System Design}

\subsection{User-centered design}

The user-centred design process of the POWER approach depicted in Figure 1 incorporates the ongoing consultation of different stakeholders during the development process, which started with the user requirements elicitation activities, continuing with the evaluation of consecutive prototype releases and the implementation of engagement approaches within the collective awareness platform, and finally culminating with the assessment of the system's impact (Strzelecka, Riley, Ozawa-Meida, Novak, Becker, Pianosi, et al. 2018).

Feedback is a key part of this process in order to enhance the effectiveness of the sharing of knowledge and experience. Workshops are a relevant physical (offline) engagement channel for eliciting user needs and for collecting feedback from target groups in a relax and more personal environment to further understand their concerns, perspectives and positions on water issues in their local context. Lessons learned at each stage of the usercentred design process are input into the platform development process (functionalities and content) enabling improvements and further implementation of the engagement approaches (Manara, Pianosi, Tavanti, Ferrari, Ozawa-Meida, Becker et al. 2019).

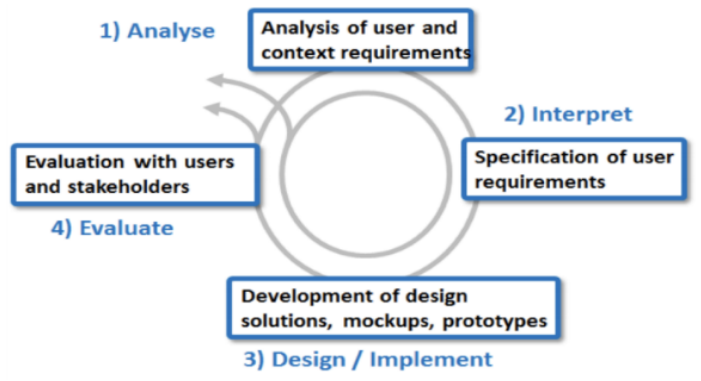

Figure 1: User-centred design process User-centred design process 
Workshops are an important tool to engage with citizens in a bi-directional and interactive communication and provides opportunities for dialogue and mutual learning. They are an integral part of the combination of online and offline channels used in POWER as they allow:

- Establishing relationships between partners and the target groups on understanding water issues in the local context.

- Making specialised knowledge about water widely understandable for the general public.

- Translating concrete and everyday problems and concerns of the public into an expert dialogue.

- Having the opportunity to listen and discuss the concerns, perspectives, positions, questions and feedback from participants.

- Involving the different stakeholder makes the user-centred design process of higher quality.

Following the in-person (physical) environment of the workshops, the online tools (provide further opportunities for partners and other stakeholders (scientists and experts) to interact and engage with each other and with the target groups, with the added benefit of lower transaction costs and within their time availability (Elelman, Becker, Drenska, Fernandes, Coelho, Koop et al. 2019).

\subsection{Gamification and acquired knowledge visualization}

Gamification and knowledge visualization are important pillars of the POWER approach. Based on end- user needs, an incentive model has been constructed that encourages the use of the platform functionalities by all stakeholders involved taking into account the knowledge of different local communities, and promotes the achievements of KDC specific water- related objectives. Gamified incentives are incorporated both in the design of the local DSPs for the KDC as well as into the global DSP layer powering the best practice repository, stimulating the engagement of a wider audience of stakeholders and follower cities (Deterding, Khaled, Nacke, \& Dixon 2011).

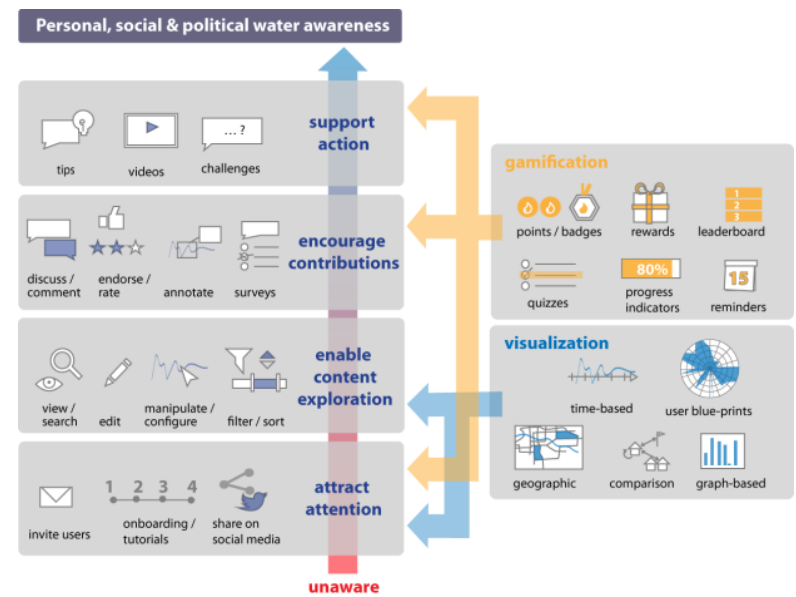

Figure 2: Gamification as an accelerator for gaining personal, social and political water awareness on the platform 
On the POWER platforms, gamification aims to support users in gaining personal, social \& political awareness by attracting the users' attention, encouraging contributions such as engaging in a discussion or taking a survey, and supporting user action on the platform, e.g. reading content, taking up challenges, or attending city events on related sustainability topics. The POWER platform combines different gamification elements and mechanisms such as progress feedback, points, badges, and rewards (see Figure 2). In order to cater to different types of users motivated by different types of motivations (e.g. personal achievement, social recognition, social comparison), the gamification model has been informed by the consideration of user and player models from literature, that describe different types of users with respect to their primary motivational drivers (Orji, Nacke, \& Di Marco 2017), as well as by studies on motivational drivers in commons-based peer production (Zhang 2008; Vassileva 2012). To this end, a mix of tools has been defined combining different elements such as feedback mechanisms, the sense of purpose and personal achievement, collaboration for collective good, social recognition and community identification which form the basis of the gamification model, with competitive elements being used primarily at the level of inter-city comparison and to a limited extent in combination with personal achievement (e.g. in addition to personal achievement rewards, selecting best contributions for special symbolic or social recognition). In this way, the gamification model in connection with the engagement models avoid the biases of traditional gamification, which can fail to address user types that don't respond to competition as a primary motivational driver (e.g. gender bias).

To motivate users towards gaining personal, social and political water awareness on the platform and to being more active, the platform presents them with a gamified knowledge visualization for monitoring their progress, their awareness blueprint. The users' score and awareness level is shown in a type of radar chart. It shows the users' progress based on the actions they do on the DSP along three domains, i.e. 'personal', 'social' and 'political awareness' (see Errore. L'origine riferimento non è stata trovata.). The 'Personal' awareness score displays the user's efforts to get engaged with a given pilot topic and to take actions the user personally benefits from, the 'Social' score reflects efforts to take actions both the user and the other people in the city benefit from, and the 'Political' score reflects efforts to take actions both the user and the city council benefit from. Each domain is divided into three knowledge dimensions (vectors, when referring to more traditional radar charts): Problem Awareness, Practical Knowledge, and Readiness for Action. Different actions on the platform typically contribute more to one of these knowledge dimensions per domain and less on others. E.g., reading a section about the water quality in a certain neighbourhood mainly contributes to gaining problem awareness on a social level, reading practical tips e.g. how to protect oneself against flooding mainly contributes to gaining practical knowledge on a personal level, and engaging in local events organized by the city to getting ready to act on a political level.

An overall community awareness blueprint for a city (collective awareness) is also calculated by averaging the awareness of all the users of the collective awareness platform in a given pilot. With this community blueprint, a user can compare his own progress to his community's progress. Ultimately, different communities working on the 
same topics can also compare their overall progress amongst themselves. Moreover, this collective visual awareness blueprint is also an instrument for the city to monitor, which areas of awareness (personal, social or political) develop better and which less well, and hence identify where additional action is needed (Koroleva, Calvillo Gámez, Miranda \& Novak 2018).

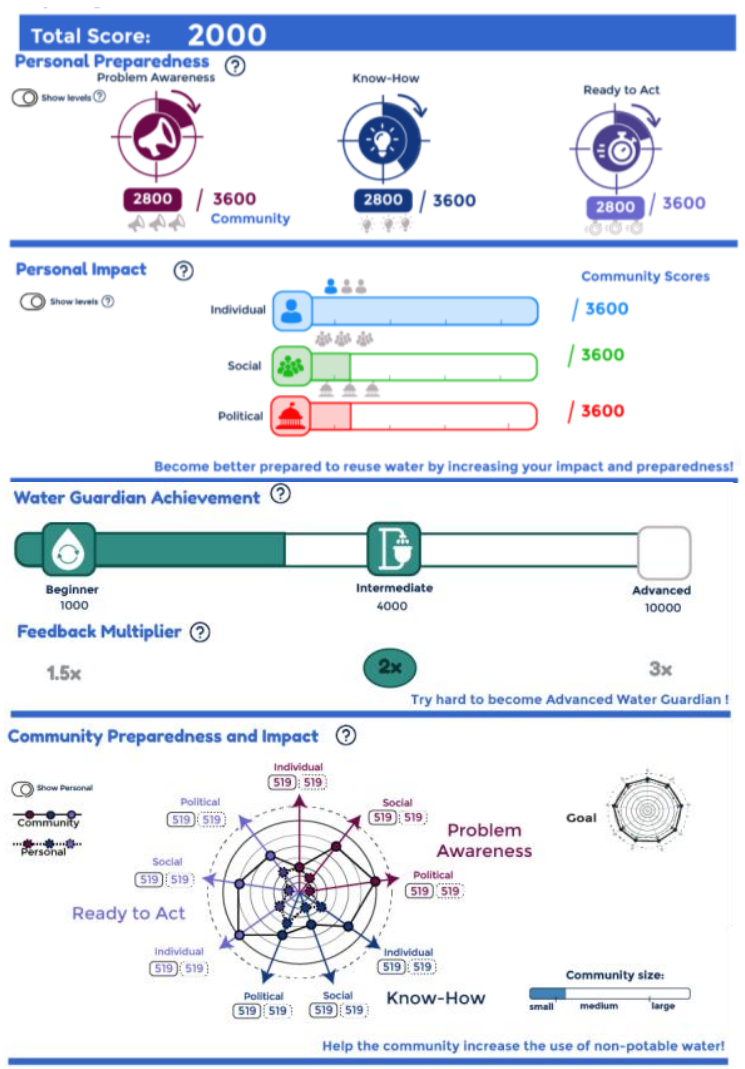

Figure 3: Snapshots of personal and community awareness blueprints in the example of the Leicester collective awareness platform

\subsection{Integration of geographical information and real-time data}

Local representation is a key factor for engagement as it enables users to find information that is more relevant for them. This is especially important in the context of sustainability where existing global problems such as climate change or biodiversity loss are often perceived as too big and too far away for the individual who as a result feels overwhelmed and powerless to do something about it. The need to connect urban sustainability challenges to the locality of the citizens and to offer them a possibility to locate themselves within an area affected by a given issue supports the involvement of the target groups. Knowing that one's own property lies within an area that is prone to surface water flooding in the example of Leicester is an important driver to learn more 
about flood risk issues and may lead to active involvement in risk reduction measures. To support that, the map window enables the collective awareness platforms to have an extended geographical capability in expressing issue-related information and interacting with the user, who benefits from information layering, geographical search capabilities (including postal codes in many countries), distance measurements and other tools (Coelho, Nunes, Fernandes \& Vitorino 2018b).

\section{Do you know your flood risk?}

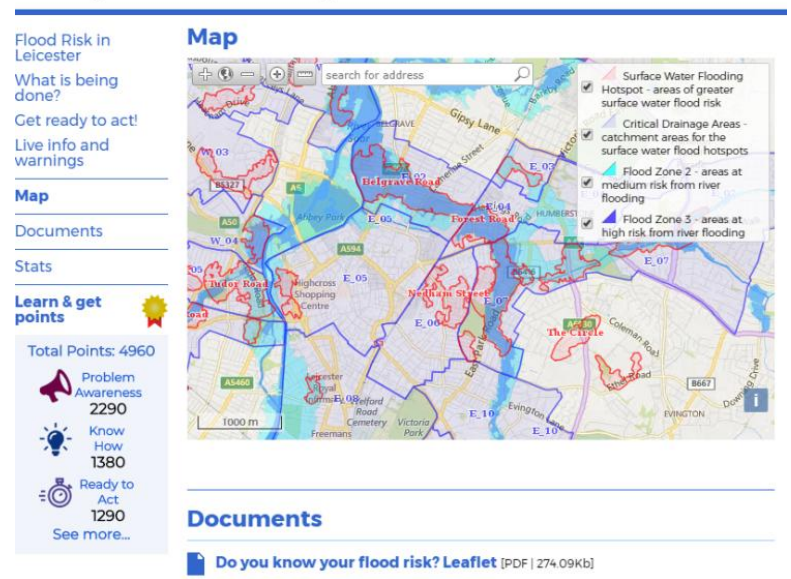

Figure 4: Integration of geographical information increasing engagement by making local affectedness of flood risk visible

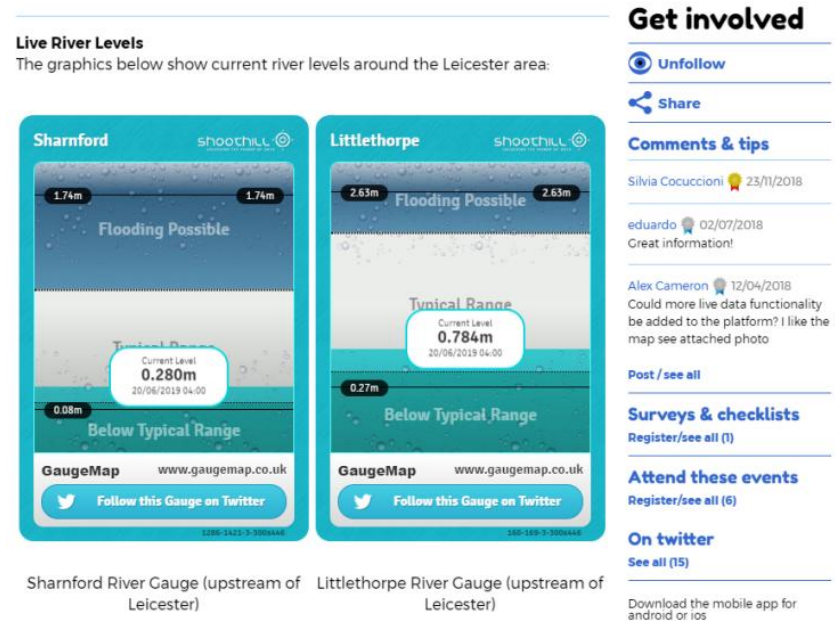

Figure 5: Integration of real-time river level information enabling quicker responses to flooding events

Similar to local relevance, the timely provision of relevant information is another important factor in designing a platform that provides additional value to citizens because it enables more immediate decisions. In the case of river flooding for example, being able to monitor river levels in real-time is crucial to take action as soon as possible 
when the water level rises above a critical threshold. Therefore, the POWER platforms enable the integration of such monitoring information in real time by accessing open data portals or third-party widget providers (see Errore. L'origine riferimento non è stata trovata.).

\subsection{User interface design}

The platform's design is key in providing a smooth user experience and has great influence on the public users' engagement in the topics addressed. Design also affects participation collection, in the sense that actions to be performed by the public users must be accessed on visible places and unambiguous ways. A significant and specialized effort has been undertaken to create an appealing layout that retains the user's attention, with icons and structured sections, in order to direct the user's attention to the important participation actions (Coelho, Nunes, Fernandes \& Vitorino 2018c).

Cross-browser and cross-operating system compatibility was also a concern, as the guidelines stipulate that the platform's user experience should be as homogenous as possible for every platform. The content displayed is divided into topics designated as 'challenges', and these challenges may be subdivided into sections, which correspond to thematic break-down elements of the content. Users are encouraged to participate by performing certain actions on the challenges. The main participation actions are:

- Sharing a challenge in a social network

- Following a challenge: the PUB sends emails about updates on the challenges followed by the users

- Commenting a challenge and/or taking part in discussions

- Giving a tip on a challenge

- Marking a challenge section as understood

- Answering a survey

It is very important that these actions are easy to perform, in order not to have any obstacles in collection participation (Coelho, Nunes, Fernandes \& Vitorino 2018c).

\section{Outcomes: Evaluation Results}

For the POWER project as for most environmental ventures, the necessity at a local level for a deliberate nurturing of public awareness, leading to citizen concern, interest and a desire to participate in what would lead to the existence of more proactive as opposed to reactive local governments would further underline the fact that the use of an effective collective awareness platform within a coherent socio-political approach to a specific issue can be key to addressing the challenges which society faces at present. In order to achieve this, it was essential to establish a working relationship with interested and relevant stakeholders at a local level. Therefore, POWER organised three series of workshops in each of the four pilot cities. The first round of workshops held during the course of 2018 focused on gathering participants' reactions which, in turn could be employed within the further development and improvement of the platform. The second round of workshops followed at the beginning of 2019 focusing on evaluating the user 
acceptance and the impact of the collective awareness platform. In addition, a third round of workshops was designed to mobilize local knowledge and to foster userengagement with the platform (Elelman, Becker, Drenska, Fernandes, Coelho, Koop et al. 2019).

\subsection{Workshop round 1: End-user feedback}

In total, 30 participants took part in the four round 1 workshops held in each pilot city in 2018 and their feedback on the first version of the platform was obtained by the discussions which took place during the workshops themselves, questionnaires which they completed at the end of the workshops and their subsequent input on the platforms. Participants welcomed the initiative as a whole and the collective awareness platform at hand, which was perceived as an attractive tool to raise awareness for the respective water issue among the general public and as a new channel for authorities and citizens to interact. They liked the interactive concept of the platform often accompanied by the wish to further extend its discussion elements to interact even more with likeminded groups in different cities. The use of gamified elements was welcomed as an innovative approach for this kind of platforms with a high potential to attract different target groups. People present at the workshops have also been highly motivated to and constructive in suggesting different ways of further improving the platforms. For instance, one controversial element discussed in all workshops was the initial registration box which at the time had been very prominently placed at the top of the starting page. Similarly, some specific elements used in the initial presentation of the gamification model have not been completely clear to some users. These comments have been taken up in the redesign of the platform and the subsequent evaluation of these elements has shown that these issues have been addressed successfully. Another concern raised in the discussions has been that some of the contents published on the local platforms might appear 'too dry and scientific' to some audiences (e.g. younger generations) and consequently platform contents have been further improved and tailored to their heterogeneous target groups (Elelman, Becker, Drenska, Fernandes, Coelho, Koop et al. 2019).

\subsection{Workshop round 2: Technology acceptance and social impact}

The main purpose of round 2 workshops held in 2019 with 35 participants in total over all four four pilot city events has been to evaluate the technology acceptance of the water community platforms and its usability with local actors. In order to achieve this goal, the evaluation of the platform has been based on current scientific literature in the field such as the UTAUT2 framework provided in Venkatesh, Thong \& Xu (2012), collecting feedback both quantitatively, using questionnaire-based instruments and also qualitatively in the form of qualitative results of semi-structured discussions. The questionnaires were structured in the same way for all cities using the same set of questions differing only inasmuch as the different water-related challenges in the cities diverge. The questions assessing attitudes and beliefs used a Likert scale ranging from 'Strongly disagree' (1) to 'Strongly agree' (5).

With regards to overall awareness on the water issue at hand, participants were very conscious about the topic with $97 \%$ somewhat or strongly agreeing that it is very 
important for their city. Similarly, a large majority of $74 \%$ somewhat or strongly agreed that they pay particular attention when they see or hear a story about the water issue. These answers could indicate that the participants have already been well aware about the respective issue. On the other hand, answers to such questions are often influenced by social norm expectations. Results further demonstrate that participants in all 4 cities found the water community platform useful (71\% agreed, $20 \%$ neutral, $9 \%$ disagreed), easy to use (60\% agreed, $20 \%$ neutral, $20 \%$ disagreed) and enjoyable (57\% agreed, 29 $\%$ neutral, $14 \%$ disagreed). This confirms that the platforms have been capable of presenting water-related information in an easily understandable and also in an enjoyable way. Considering that water issues are generally difficult to present in attractive and engaging manners, this is an important success of POWER. The participants also assessed that the platforms had a positive impact on increasing their awareness regarding the water issue in their city (86\% agreed, $14 \%$ neutral, $0 \%$ disagreed). Accordingly, they stated that it helped them to better prepare for the challenge at hand - both individually (83\% agreed, $11 \%$ neutral, $6 \%$ disagreed) and as a community (80\% agreed, $17 \%$ neutral and $3 \%$ disagreed). The same is true for the perceived usefulness of the platform to monitor their own preparedness to tackle the water-related challenge in their city (80 $\%$ agreed, $14 \%$ neutral, $6 \%$ disagreed).

The overall positive assessment of the platform's design, usefulness and impact reflected in the responses to the questionnaire was also clear from the qualitative feedback that participants provided in all 4 workshops. They stated that "the platform is highly interactive", providing a "novel approach", being "aesthetically pleasing and easy for the eye to navigate", "informative", and that it had "great potential to provide focused information". Participants also praised the "social aspect to engage other communities" and that the platform "incentivises participation". In line with the very positive results of online crowd evaluation of the gamified elements, participants in the workshops also particularly liked those elements. Naturally, participants also provided their ideas for further improvement of the platform and its contents. Several participants suggested making the content even more local by, for example, creating idea contests for neighbourhoods or by showcasing news and initiatives at a district level. Another means of improvement was discussed by further tailoring the contents according to the knowledge of each of the different target groups the platforms are addressing, for example by creating sections dedicated to school children only or by providing a type of "quick emergency info kit" for people affected by a flood in Leicester. The platform's functionality was generally perceived as good while some elements were also suggested to further improve its usability, for example by adding a search function to facilitate finding specific contents.

\subsection{Workshop round 3: Ideation and knowledge mobilization}

One of the main objectives of the POWER project is to obtain the direct involvement of citizens and to engage them with and support knowledge mobilization for water and sustainability topics. Therefore, innovative workshops for design thinking were created, developed and successfully conducted in order to facilitate and support the development of innovative ideas that offer solutions to local sustainability and waterrelated problems, and to provoke knowledge mobilisation among citizens regarding 
water and sustainability topics. A total of 8 idea and knowledge mobilization workshops took place in Leicester, Milton Keynes, Cranfield (near Milton Keynes), Sabadell, Berlin and Sofia in the period November 2018 - January 2019 that attracted a total of 85 participants ${ }^{1}$.

Built on Google's Design Sprint methodology, the workshops are conceptualized and function in a similar way: citizens identify the most pressing challenges in a given field, generate ideas that address these problems, develop first prototypes (sketches) of the solution approaches and upload them to the POWER platform as a way to test and refine their ideas by collecting feedback from the platform communities and refining their solutions accordingly.

The POWER idea and knowledge mobilization workshops are a combination of individual and group work, creative tasks, feedback rounds, common and individual decision making and the whole process is guided by a trained facilitator. The whole 4 to 8 hours long session is strictly timed and divided into clearly defined and easy to perform single tasks, which allows the participants to progress step wisely. Combined with a longer introduction into the topic in the beginning of the workshop, this structure ensures that even not tech-savvy participants with no previous knowledge in sustainability or innovation topics can successfully take part in the session and create solutions to local ecological and water-related problems. This ensures the inclusiveness of the process and allows a broader range of citizens to participate in the workshops, learn more about ecological issues in their communities, develop concrete solutions that tackle these issues in a co-creative and open-collaboration process and receive collective feedback for their solutions.

As a result of the workshops, 70 different ideas for solutions to pressing sustainability issues were created and uploaded to the four POWER platforms. Between $70 \%$ and $90 \%$ of the participants agreed or strongly agreed that the workshops met their expectations, were well organized and structured, made them think about how to create concrete solutions to sustainability issues and motivated them to engage with other POWER events.

\section{Implications}

Common to most sustainability issues is a general lack of knowledge and awareness, leading to a perceived low local priority and initiatives aiming to increase collective awareness for them usually face the challenge of low user engagement. The POWER approach to introduce behavioural interventions integrating physical and digital engagement activities has proven effective in nurturing participation in the pilot cities. In the design and development of our collective awareness platform, the involvement of as many different end-users from the relevant target groups was vital in order to elicit their expectations and needs as early as possible. Such feedback loops should be repeated at different points in an iterative user-centered design process continuously fostering user

${ }^{1}$ Idea mobilization sessions took place also in non-pilot cities in order to 1) test the workshop concept in different contexts and 2) show how water-related challenges are similar in many places in Europe and thus encourage the participants to think local sustainability issues as interconnected with European and global ecological topics. 
feedback through, incorporating it into the development and testing it again with the target audience. Interactive workshops are a suitable approach if such sessions seek proactive, constructive input from the participants. Creative event concepts as applied in the ideation and knowledge mobilisation workshops can also facilitate the development of innovative ideas that offer solutions to local sustainability problems, and provoke knowledge mobilisation among citizens regarding such topics and can be used to further drive interaction with the platform. Furthermore, gamification and appropriate knowledge visualisation techniques have also been applied successfully to further support end-user engagement with the water-related sustainability challenges at hand. Such elements should by integrated in similar ventures in order to help addressing the different types of motivations citizens may have with regards to sustainability challenges.

\section{Acknowledgements}

This research is a part of and sponsored by the Horizon 2020 project "POWER - Political and social awareness on water environmental challenges" under Grant Agreement N 687809 .

\section{References}

Böckle, M., Novak, J. \& Bick, M. (2017): “Towards Adaptive Gamification: a Synthesis of Current Developments." Twenty-Fifth European Conference on Information Systems (ECIS).

Coelho, S.T., Nunes, S., Fernandes, T., Vitorino, D. (2018a): "D2.1 General architecture, functionalities and analysis report." POWER project deliverable. Available: https://www.power-h2020.eu/wpcontent/uploads/D2.1.pdf, [Accessed: 07-June-2019].

Coelho, S.T., Nunes, S., Fernandes, T., Vitorino, D. (2018b): "D2.3 DSP PUB software - Beta release report." POWER project deliverable. Available: https://www.power-h2020.eu/wpcontent/uploads/D2.2.pdf, [Accessed: 07-June-2019].

Coelho, S.T., Nunes, S., Fernandes, T., Vitorino, D. (2018c): "D2.3 DSP PUB software - Beta release report." POWER project deliverable. Available: https://www.power-h2020.eu/wpcontent/uploads/D2.3.pdf, [Accessed: 07-June-2019].

Deterding, S., Khaled, R., Nacke, L. E. \& Dixon, D. (2011): “Gamification: Toward a definition.” CHI 2011 gamification workshop proceedings (Vol. 12). Vancouver BC, Canada.

Elelman, R., Becker, M., Drenska, K., Fernandes, T., Coelho, S., Koop, S. et al. (2019): "D4.3 Report on the Workshops". POWER project deliverable. Not yet published.

Hassenzahl, M. (2004): "The interplay of beauty, goodness, and usability in interactive products." Humancomputer interaction, 19(4), 319-349.

Irwin, A. (2001). Constructing the scientific citizen: science and democracy in the biosciences. Public Understanding of Science, 10(1), 1-18.

Koroleva, K., Calvillo Gámez, E. H., Miranda, D., Novak, J. (2018): "D3.3 Report on the Gamification Model." POWER project deliverable. Available: https://www.power-h2020.eu/wpcontent/uploads/D3.3.pdf, [Accessed: 08-June-2019].

Krueger, R., Tuler, S. \& Webler, T. (2001): "What Is a Good Public Participation Process? Five Perspectives from the Public", Environmental Management, vol. 27, no. 3, pp. 435-450.

Manara, G., Pianosi, M., Tavanti, L., Ferrari, L. Ozawa-Meida, L., Becker, M. et al. (2019): "D3.4 Report on the engagement model." POWER project deliverable. Available: https://www.powerh2020.eu/wp-content/uploads/D3.4.pdf, [Accessed: 07-June-2019]

Petts, J. \& Brooks, C. (2006): "Expert Conceptualisations of the Role of Lay Knowledge in Environmental Decisionmaking: challenges for Deliberative Democracy", Environment and Planning A, vol. 38, no. 6, pp. 1045-1059. 
Renn, O. (2008). "White paper on risk governance: Toward an integrative framework." In Global risk governance (pp. 3-73). Springer.

Strzelecka, A., Riley, J., Ozawa-Meida, L., Novak, J., Becker, M., Pianosi, M. et al. (2018): "Building awareness and active citizen participation for water challenges." 1 st International WDSA / CCWI 2018 Joint Conference, Kingston, Ontario, Canada -July 23-25, 2018.

Vassileva, J. (2012): "Motivating participation in social computing applications: a user modeling perspective." User Modeling and User-Adapted Interaction, 22(1-2), 177-201.

Venkatesh, V., Morris, M. G., Davis, G. B. \& Davis, F. D. (2003): "User acceptance of information technology: Toward a unified view." MIS quarterly, 425-478.

Venkatesh, V., Thong, J. Y. L., Xu, X. (2012): Consumer acceptance and use of information: extending the unified theory of acceptance and use of technology. MIS Quarterly (36:1), pp. 57-178.

Webler, T., Kastenholz, H. \& Renn, O. (1995): "Public participation in impact assessment: A social learning perspective", Environmental Impact Assessment Review, vol. 15, no. 5, pp. 443-463.

Zhang, P. (2008): "Technical opinion Motivational affordances: reasons for ICT design and use." Communications of the ACM, 51(11), 145-147. 